\title{
Innovative supply chain optimization models with multiple uncertainty factors
}

\author{
Tsan-Ming Choi ${ }^{1} \cdot$ Kannan Govindan ${ }^{2} \cdot \mathrm{Xiang}_{\mathrm{Li}^{3}}$. \\ Yongjian $\mathrm{Li}^{4}$
}

Published online: 6 September 2017

(C) Springer Science+Business Media, LLC 2017

\begin{abstract}
Uncertainty is an inherent factor that affects all dimensions of supply chain activities. In today's business environment, initiatives to deal with one specific type of uncertainty might not be effective since other types of uncertainty factors and disruptions may be present. These factors relate to supply chain competition and coordination. Thus, to achieve a more efficient and effective supply chain requires the deployment of innovative optimization models and novel methods. This preface provides a concise review of critical research issues regarding innovative supply chain optimization models with multiple uncertainty factors. It also introduces the special issue's research papers and their respective insights.
\end{abstract}

Keywords Supply chain management $\cdot$ Multiple uncertainty factors $\cdot$ Risk management

\section{Introduction}

Our business world is increasingly uncertain and vulnerable. Historical data indicate that the total number of natural and man-made disasters has increased dramatically over the last 10 years. These include terrorist attacks, wars, earthquakes, economic crises, strikes, computer virus attacks, and so forth (see, for example, the statistics by the Centre for Research on the Epidemiology of Disastersat www.cred.be, and Choi et al. 2016). Besides the above unpredictable disasters, inherent supply chain uncertainties, such as random production yield,

\footnotetext{
Kannan Govindan

kgov@iti.sdu.dk

1 Institute of Textiles and Clothing, The Hong Kong Polytechnic University, Hung Hom, Kowloon, Hong Kong

2 Center for Sustainable Supply Chain Engineering, Department of Technology and Innovation, University of Southern Denmark, 5230 Odense M, Denmark

3 College of Economic and Social Development, Nankai University, Tianjin 300071, People's Republic of China

4 Business School, Nankai University, Tianjin 300071, People's Republic of China
} 
lead time variation, stochastic demand, stochastic capacity, fluctuating price, and floating currency may lead to catastrophic economic consequences. What is worse, multiple types of random factors and disruptions coexist and combine with each other, which may cause further damage to supply chains in today's complex business environments (Arena et al. 2010, 2011; Wu et al. 2014). In response, both industry and academia are striving to develop and to implement new operations research solutions to better manage the supply chain risks (Heckmann et al. 2015; Snyder et al. 2016; Lawrence et al. 2016).

This special issue is motivated by the importance of addressing the challenges faced by supply chain systems in the presence of multiple uncertain factors. It focusses on three crucial areas of innovative supply chain optimization models, including supply chain operations processes, competition and interactions in supply chains, and supply chain contracting and coordination. In the following sections, we first concisely examine each of these areas. Then we introduce the corresponding papers selected for this special issue. Finally, we summarize the results and present the core insights and findings.

\section{Supply chain operations processes}

In current practices, almost each process and decision in the supply chain system is associated with uncertainty (Lalmazloumian et al. 2016). Although a particular type of disruption (earthquake, terrorist attack, fire, strike) may occur infrequently, the large number of random factors and events makes the likelihood quite high that some disruptions will affect supply chain operations. In particular, proper risk management schemes are critically important, and they are studied as one of the most popular topics in today's global business environment.

There are some recently published review papers on risk management in the supply chain operations processes under uncertain environments. For example, Colicchia (2012) use a rigorous literature review methodology, called systematic literature network analysis, to identify future research directions of supply chain risk management and to recognize streams of research that appear to be most promising. Heckmann et al. (2015) systematically define supply chain risk concepts, terminologies, and risk measuring and modeling methods from related fields. Fahimnia et al. (2015) use bibliometric and network analysis tools to identify key research clusters/topics, interrelationships, and generative research areas on quantitative models for managing supply chain risks. Chiu and Choi (2016) review the use of mean-risk models for analytical supply chain risk analysis. Govindan and Jepsen (2016) review the risks related to suppliers in service supply chains. Snyder et al. (2016) examine operations management literature on supply chain disruptions and provide an overview of the research within six supply chain processes.

The following papers relate to specific supply chain operations processes, including network design, procurement, inventory and transportation logistics, pricing at the market end, and other issues involving decisions at the layers of strategies and tactics.

\subsection{Network design}

Supply chain network design (SCND), also called strategic supply chain planning, is a part of the planning process in SCM and it determines the infrastructure and physical structure of a supply chain. Supply chain network design is a popular topic in the literature (Nagurney et al. 2016) and SCND under uncertainty has gained considerable attention in both practice and academia during recent years (Govindan and Fattahi 2017). Four papers fall into this area. 
First, Zokaee, Jabbarzadeh, Fahimnia, and Sadjadi (2017) investigate a robust optimization problem for supply chain design in which the strategic location decisions and tactical allocation decisions are made to minimize overall costs. A basic deterministic model is first proposed, and then a more complex model is extended with the considerations of multiple uncertainties in demand, supply capacity, and cost. The methodology employed is the robust optimization approach, which can overcome the limitations of scenario-based solution methods in a tractable way, i.e., without excessive augments in complexity of the underlying deterministic model. Real data-based analysis is used to show that the developed models can be applied to the network design of a supply chain of bread production and distribution.

In the next paper, de Matta (2017) develops a stochastic programming model of a supply chain network design problem which integrates logistics and transfer pricing decisions. The production capacities are regarded as random factors and the corresponding effects of supply disruptions are considered. The stochastic model is transferred into an equivalent deterministic model utilizing chance-constrained programming, and then solved through a decomposition-based procedure. A computational study is conducted to demonstrate the efficacy of the proposed model. It is found that reserving capacity and increasing volume flexibility can reduce the need of price inflation in response to tightening capacity conditions due to production disruptions.

Bell and Chen (2017) consider a stochastic supply chain network of multiple plants supplying multiple markets with a single product. The research motivation is to explore the relationship between decision making at various levels within the firm and, in particular, between the firm's strategic and operations decision making. Three protocols for decision making are considered, namely, supply chain optimization (SCO), revenue management $(\mathrm{RM})$, and the integration of supply chain optimization and revenue management (RM$\mathrm{SCO}$ ). It is shown that that either SCO or RM may provide poor operations level decisions, particularly if marketing, production, and logistics decision-making choices are not very tightly integrated. On the other hand, RM-SCO can bring a significant benefit to manufacturers who can successfully integrate production, logistics, and marketing decision making. Such integration will improve operations level decisions and provide an improved platform for tactical and strategic decisions.

Finally, Jindal and Sangwan (2017) close the stochastic supply chain loop by incorporating the reverse flow of products. Specifically, they explore a closed-loop supply chain network design problem under consideration of multi-product, multi-facility, and multi-customer zones. They incorporate a basic trade-off between the economic objective (measured by profit) and the environmental objective (measured by carbon footprint), and they formulate the problem as a multi-objective optimization one. The uncertainties related to ill-known parameters are represented by triangular fuzzy numbers, and a fuzzy multi-objective optimization model is formulated correspondingly. The model is solved by the $\varepsilon$-constraint method, and its application is demonstrated through an illustrative example.

\subsection{Procurement}

Procurement is seriously affected by supply side risk. Results from a 2012 survey report, conducted by Supply \& Demand Chain Executive and IHS Inc., showed that almost 64\% of the respondents believe that managing supplier risks in operational planning is either very significant or the most significant. The results also found that the top three benefits of managing supplier risks are reduced costs, improved continuity of supply, and improved reaction time towards supply chain disruptions (Supply \& Demand Chain Executive and IHS 2012). 
Motivated by the price volatility of commodity items, Nie, Boyac1, Gümüs, Ray, and Zhang (2017) analyze an optimal joint bidding and procurement strategy for a firm that faces supply-side risk in terms of raw material prices, as well as demand-side risk in terms of project arrivals. The problem is formulated as an infinite-horizon stochastic dynamic program and its structural properties are analytically characterized. It is proven that the optimal procurement strategy follows a price-dependent base-stock policy and the optimal bidding price decreases with respect to the inventory level. Three heuristic strategies are developed, and the situations under which each strategy is more applicable are analyzed through a comprehensive numerical study. A critical source of supply uncertainty stems from the randomness of unreliable suppliers.

$\mathrm{Li}$ (2017) considers a firm that sources from two unreliable suppliers to satisfy a deterministic demand. One supplier is subject to an "all-or-nothing" supply disruption, and the other supplier confirms with a random fraction production yield. The author studies the models of no recourse (Model NR) and those of ordering with recourse (Model O1R and Model O2R), while he characterizes the conditions under which single sourcing or dual sourcing should be adopted. For dual sourcing strategies, he finds that demand is equal to a linear combination of optimal order quantities under Model NR, the optimal order quantity is equal to that of a revised single sourcing problem under Model O1R, and the optimal order quantity follows an all-or-nothing style under Model O2R.

\subsection{Logistics operations}

Logistics management is a crucial part of supply chain management which includes transportation, storage, and inventory. Many organizations outsource their logistics activities partially or entirely to third party logistics service providers (Govindan and Chaudhuri 2016).

Liu, Yang, Wang, and Bai (2017) explore the influences of the uncertainties of the functional logistics service provider's (FLSP's) operation and customer requirements on the optimal scheduling decisions within a logistics service supply chain (LSSC). A multi-objective programming model for the LSSC scheduling problem is established. The optimization problem aims to minimize the total order operation cost in the LSSC, to minimize the difference between the total expected operation time and the customer requirement time, and to maximize the satisfaction of FLSPs. A genetic algorithm approach is applied to solve the problem after the multi-objective programming model is transformed into a singleobjective model. The influences of some relevant parameters on the scheduling performance are investigated with a numerical analysis. One major finding is that the time windows of the FLSP's operation and customer requirement have a significant interrelationship.

Thorsen and Yao (2017) propose a robust optimization modeling framework for an inventory control problem subject to uncertain lead times and uncertain demand. They use a Benders' decomposition approach to develop the optimal inventory policy parameters, which do not require the knowledge of random variable distributions and order crossovers. Their numerical study compares the performances between their proposed approach and the sample average approximation (SAA) method, and it indicates that the proposed approach provides more stable and robust solutions, especially when the realized distribution is different than the sampled distribution.

Maihami, Karimi, and Ghomi (2017) consider a joint inventory and pricing optimization problem for a non-instantaneous deteriorating product. The randomness lies in product demand and the deteriorating process. Also a two-echelon trade credit policy is adopted. The conditions for the existence and uniqueness of the optimal solution on selling price and inventory decisions are provided, and an algorithm is developed to find the optimal 
solution. Numerical studies are performed to show the sensitivities of the system decisions and performances to the system parameters such as ordering cost, trade credit period, and payable interest. The results indicate that the retailer's total profit increases significantly with the consideration of the non-instantaneous deteriorating product feature and the trade credit policy.

\subsection{Pricing}

Pricing is an important consideration in supply chain operations because it affects both supply and demand, and, in turn, it influences supply chain revenue and optimal operational decisions.

Du and Chen (2017) establish a modeling framework to study the optimal pricing problem for a firm and the optimal purchase timing in the presence of strategic consumers. Random factors under consideration are the consumers' valuation with respect to the new products and the proportion of strategic consumers in the whole demand pool. The problem is solved through a game theory approach. It is found that only when the firm's discount factor exceeds a certain level should the skim-pricing strategy be adopted; otherwise, the penetration strategy should be adopted. The authors determine that uncertainty potentially diminishes a firm's opportunity to adopt the price skimming strategy, and the revealing strategy is most valuable when the firm is (almost) indifferent towards skimming and penetration.

$\mathrm{Wu}$ (2017) examines supply chain pricing decisions under the influences of consumer behavior with respect to the random consumer marginal willingness to pay (MWTP) and perception difference on "pass through" in the supply chain channel. The author considers four possible market structures: single-product monopoly, multiproduct monopoly, directchannel duopoly, and indirect-channel duopoly. By using a discrete choice model, demand is generated in connection with consumer purchase behavior. It is shown that different consumer MWTP distributions will lead to different price pass-through behaviors. The crucial role of a threshold-based divisible Mills Ratio is verified in terms of the supplier pass-through, and the pricing implications are further investigated under cost uncertainty in a supply chain system.

Zhang and Liu (2017) investigate a profit-maximizing firm that sells a short-life-cycle product. They aim to explore the joint decisions on pricing and group buying in a competing market when retailers provide emergency procurement to meet stochastic demands. Both monopoly and duopoly models are explored. The joint decisions on optimal pricing and quantity of online group buying are analyzed, and the equilibrium solutions for the retailers are derived. They find that retailers always prefer to launch group buying in a single channel, but they also observe dual channels for competing retailers due to emergency procurement.

\subsection{Other operations}

Other operations covered in the scope of supply chain operations processes include demand forecasting, revenue management, and system investment decisions.

First, Ren, Chan, and Ram (2017) conduct a comparative study on demand forecasting models of fashion products with multiple sources of uncertainty. A selected set of computational models applicable to fast fashion demand forecasting are reviewed and their strengths and weaknesses are discussed. In addition, an industrial survey is conducted to show the perceived importance of different demand forecasting systems' features. Finally, an AHP analysis is conducted to rank the fast fashion demand forecasting systems as well as to reveal supplementary insights regarding the preferences of different groups of fashion industrialists. 
Chiu, Hou, Li, and Liu (2017) apply the real options approach to the revenue management field for a service supply chain, such as found in the airline and fashion industries. More specifically, they first formulate a stock loan model with regime-switching under the consideration of the environmental uncertainties of demand and market switching time. An analytic approximation approach is proposed to develop solutions for the optimization problem. Then, they propose that a recallable air ticket for travel agents and the optimal launch time for fashion products can be mapped as two different stock loans with regime-switching and finite maturity. Various numerical examples are provided to illustrate the application of the stock loan approach to value a recallable air ticket and to determine the optimal launch time of a fashion product. Their major finding is that the rate of regime-switching and the parameter that governs time-varying strike price both play important roles in the two revenue management problems.

Motivated by the agricultural food project funded by the Chinese government, Wang, Yao, and Yue (2017) develop an e-business platform investment model to investigate the optimal investment time point for a third-party investor. By using an evolutionary discounted cash flow approach, they construct explicit forms of net cash flow with the consideration of the dynamic scheme and its evolution. Analytical results indicate that the optimal investment time point depends upon the consumers' switch rate from the physical store to the e-store and on the urbanization rate. Further, a Monte Carlo simulation is conducted to compare the effects of multiple uncertainties embedded into the system.

\section{Competition and interactions in supply chains}

Interaction and competition behaviors among supply chain members are commonly seen in practice, and the issue of multiple uncertainties makes the problem even more complicated. Observe that competition may exist vertically between the upstream supplier and downstream resellers (e.g., in Tang et al. 2014), or horizontally between the same layer of suppliers (e.g., in Babich et al. 2007) or resellers (e.g., in Tang and Kouvelis 2011). In this special issue, some papers incorporate both vertical and horizontal competitions under an uncertain supply chain environment. Information asymmetry and information sharing are also relevant hot topics.

First, Xue, Zuo, and Xu (2017) consider a two-stage supply chain consisting of one supplier and multiple retailers. The supplier produces one product and sells through multiple retailers to the same consumer market, which is perfectly competitive. The supplier can choose to adopt either the advance sale approach or the regular sale approach, and retailers decide their corresponding order quantity. Three different scenarios, the monopoly retailer, the competing retailers with information sharing, and the competing retailers without information sharing, are analyzed. The equilibrium solutions of supply chain member strategies are derived under each scenario. The authors show that it is optimal for the supplier (1) to choose the regular sale approach when retailers form as a monopoly or compete among each other with demand information sharing, and (2) to choose the advance sale approach when retailers are competing with each other without information sharing. They further explore the influences of competition, information asymmetry, and information precision to the supply chain strategies and performances.

$\mathrm{Li}, \mathrm{Li}, \mathrm{Chen}$, and Hou (2017) investigate a dual-channel supply chain consisting of a risk-neutral manufacturer and a risk-averse retailer. The manufacturer sells products through the retailer who resells it to consumers. At the same time, the manufacturer uses his own 
direct channel to sell the homogeneous product directly to consumers in the market. In their model, demand can belong to the high type or the low type, and it follows a given distribution under each type. The retailer is assumed to have more information regarding the demand than the manufacturer. The authors find that supply chain equilibrium decisions and system performances are closely related to the manufacturer's per-unit selling cost and the degree of risk aversion of the retailer. Numerical experiments are conducted to further compare the supply chain outcomes under asymmetric and symmetric market information scenarios.

Zhu (2017) uses a Stackelberg game to model an outsourcing scenario between a supplier and a buyer. In her model, the supplier's and buyer's demand forecasts are private information to each party and thus cause asymmetric information in the outsourcing contract design. Three cases, non-information sharing, information sharing, and buyer forecasting are investigated, and the equilibrium solutions are derived. The results show that the buyer, as the Stackelberg game follower, has an information advantage in the non-information sharing case. It is also found that information sharing does not always guarantee that the supplier and buyer can obtain higher expected profits compared to the non-information sharing case.

\section{Supply chain contracting and coordination}

It is well-known that the double marginalization effect in the supply chain under uncertainty would lead to supply chain inefficiency, and so it is important to develop methods to dampen it and to achieve supply chain channel coordination. Recently, it has been discovered that double marginalization may create big challenges for the supply chain under multiple uncertainties, e.g., under both supply and demand risks, compared to the traditional supply chain (Li et al. 2013). Also the required coordination contracts are much more complex under these multiple-uncertainty scenarios (Guler and Bilgic 2009; Ai et al. 2012; Li et al. 2013). Supply chain contracting is a useful measure to mitigate supply chain risk and to achieve Pareto improvement. This special issue features eleven papers that dig deeply into the areas of supply chain contracting and coordination in the presence of uncertainties.

Zhao, Wei, and Sun (2017) analyze optimal pricing strategies and the coordination issue with symmetric and asymmetric information in a two-echelon fuzzy closed-loop supply chain. Two coordinating models with symmetric and asymmetric information about the retailer's collecting scale parameter are established, and the corresponding analytical solutions are obtained. The authors prove that under the asymmetric information contract, the maximum expected profit obtained by the high-collecting-scale-level retailer is equal to that under the decentralized decision scenario, whereas the maximum expected profit obtained by the low-collecting-scale-level retailer is higher than that under the decentralized decision scenario.

Zhao, Choi, Cheng, and Wang (2017) conduct a mean-variance analysis of the commonly seen wholesale pricing contract in a single supplier/single retailer supply chain. Demand is considered to be stochastic and price-dependent. The supply chain is led by the supplier. The authors focus on exploring the efficiency of a wholesale pricing contract with the considerations of contract value risk. Their results suggest that a supply chain contract with the high expected-profit-based-efficiency tends to have a high value risk, and thus an appropriate balance between the expected outcome and the value risk associated with the contract should be pursued when designing the supply chain contract. Their findings help to explain why some supply chain contracts that are proven to be theoretically effective for achieving supply chain coordination do not work well in practice. 
Cheng, Yang, and Tsay (2017) develop an integrated model for understanding and designing more flexible and structured supply chain contracts from the perspective of the buyer, the supplier, and the system as a whole in an open supply chain, defined as when both parties have possible alternative partners. The authors demonstrate that a wide range of contract types can be viewed as a composite of fixed and flexible components, and that changing the composition alters the allocation of exposure between the contract parties, to uncertainties in both price and demand. They also suggest that the concept of relative contract value (with respect to a reference alternative) provides a means to analyze the interaction between a contract and its alternatives and quantify the ramifications of contract price uncertainty. To assist practitioners with supply contract design, different contract structures are analyzed with respect to how to configure a structured contract when the total supply chain profit is maximized, and how this profit is allocated between the parties.

$\mathrm{Fu}, \mathrm{Ma}, \mathrm{Ni}$, and Cai (2017) investigate a decentralized hybrid push-pull assembly system with multiple suppliers and one assembler, where some suppliers are stronger than the assembler and some are weaker. The authors assume that each supplier is unreliable and provides a complementary component to the assembler, which faces an uncertain demand. They analyze the pricing and production decisions of all players in such an assembly system by using a three-stage game theoretic approach. Moreover, they introduce a buyback contract (between the stronger suppliers and the assembler) and a subsidy contract (between the weaker suppliers and the assembler) to develop a mechanism to coordinate the decentralized assembly system. They show that the coordination mechanism consisting of the above two contracts can arbitrarily allocate the system profit among all players, and, thus, may achieve a desirable Pareto improvement.

Yang and Ma (2017) investigate the commonly used two-part tariff contracting scheme with asymmetric information in a supply chain consisting of one retailer and two unreliable competing retailers. In their model, the suppliers lead the game by simultaneously and independently announcing the two-part tariff contract to the retailer in the first stage. Then, all uncertainties are realized in the second stage and the retailer chooses the demand rate by setting the price to maximize his profit. The authors characterize the retailer's optimal decision and the supplier's optimal contract design. Their major finding is that a higher degree of substitution implies a lower purchasing price but a higher fixed fee. With numerical experiments, they further show that the information rent increases with the degree of substitution. However, they uncover that a larger intensity of competition is disadvantageous to the supplier.

Zha, Zhang, Yue, and Hua (2017) study the coordination issue of a service supply chain with platform effort-induced demand. The service supply chain is made up of a service provider firm, e.g., a hotel, and a service platform (such as Ctrip.com in China). Two kinds of customers are considered: the category of customers who order rooms from the hotel's front desk, and those who book rooms through the platform. Two newsvendor settings are proposed to depict the demands of the two parties independently. The major finding is that a cost sharing contract can achieve channel coordination imperfectly but, given that the cost of the sales effort is also shared, the channel is coordinated and a win-win is guaranteed if the new cost sharing contract terms are properly designed.

Liu, Li, Wu, and Zhang (2017) analyze the coordination of a supply chain under the government price regulation policy after a demand disruption has occurred. First, the authors characterize the optimal decisions of the supply chain under normal circumstance by the revenue sharing contract as a benchmark. Then, when the demand is disrupted, they redesign the contract to coordinate the supply chain and to obtain the corresponding revenue sharing 


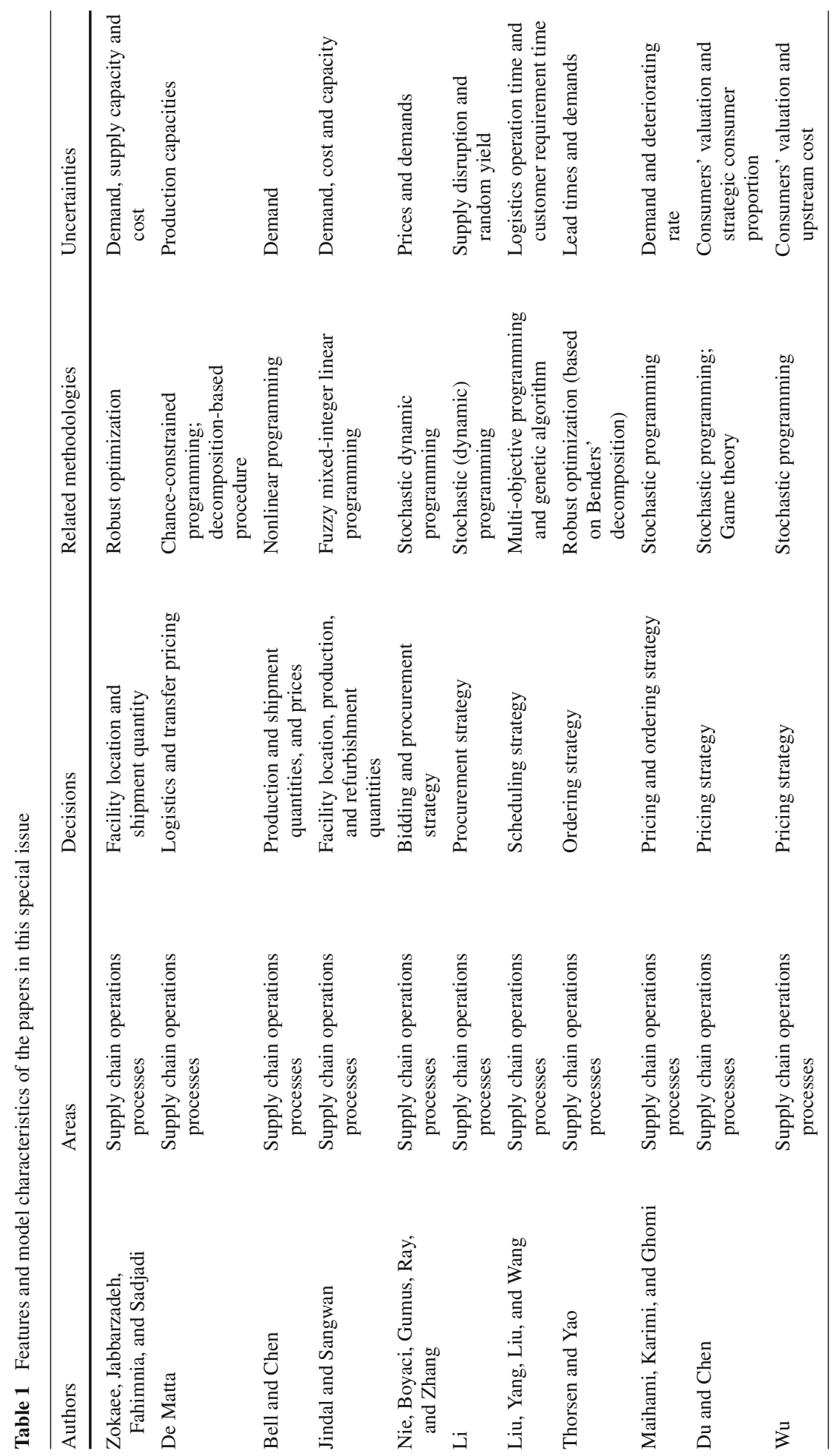




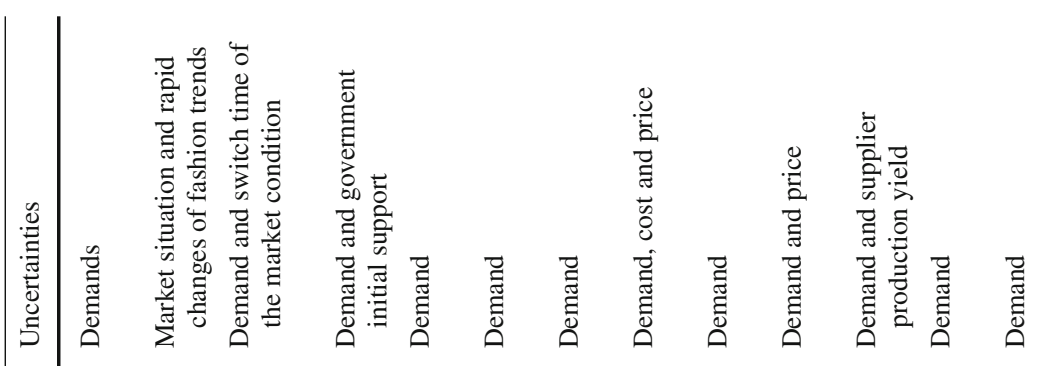

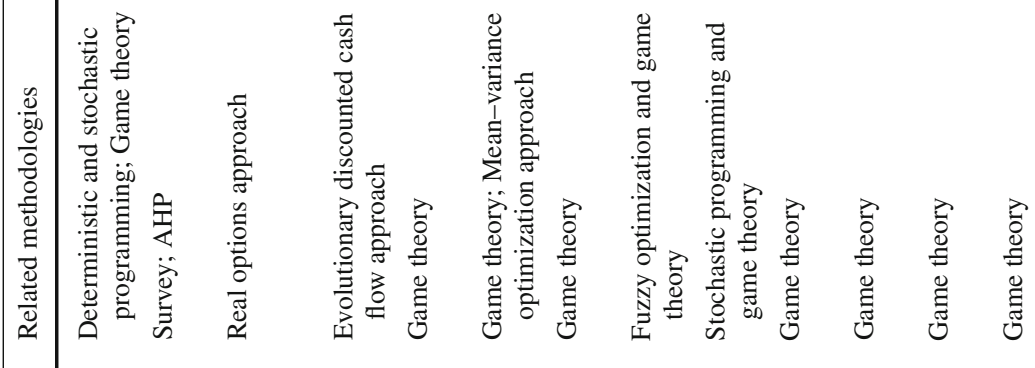

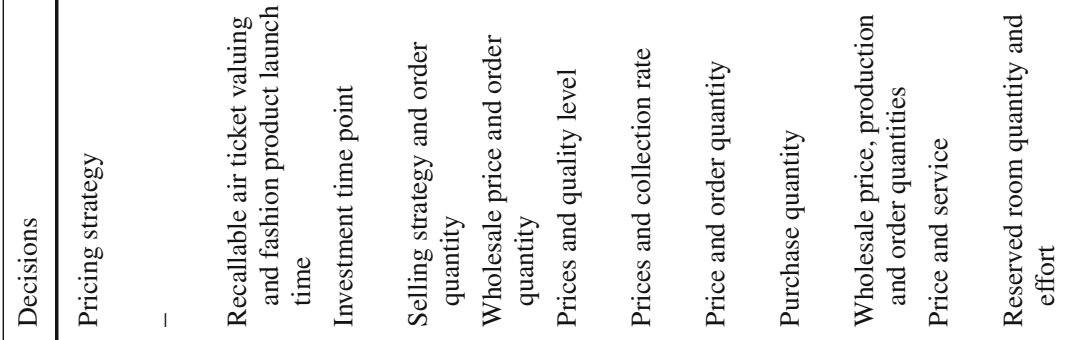

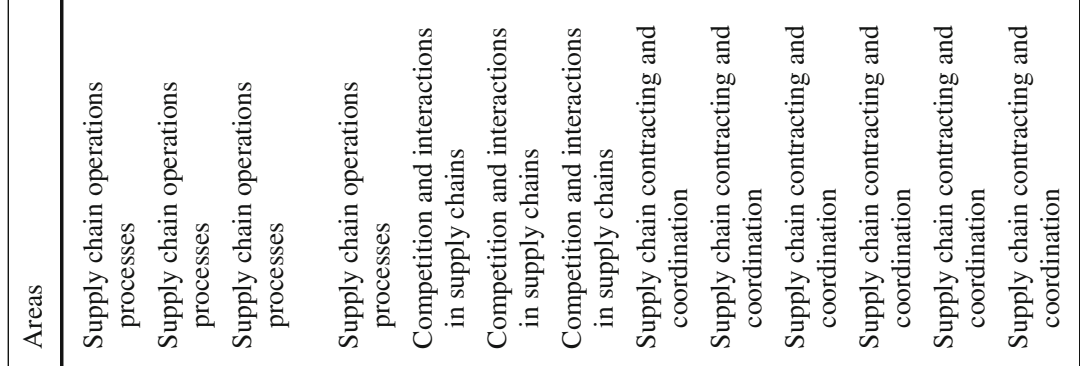

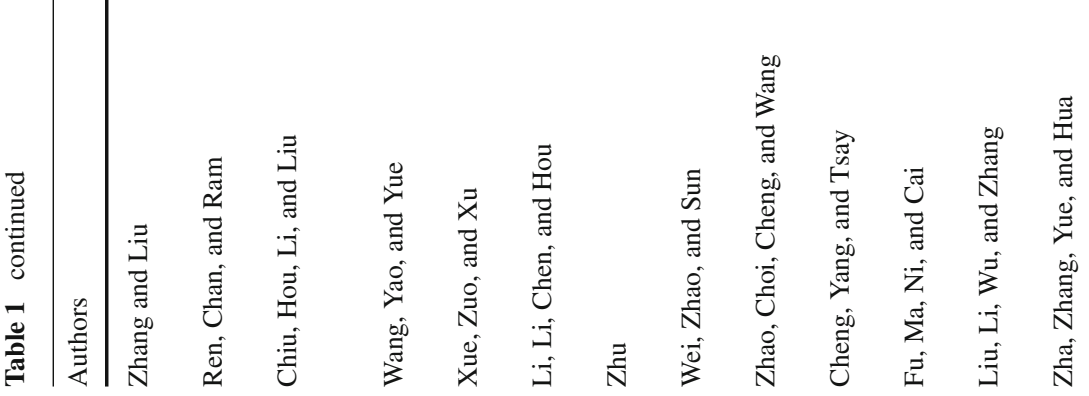




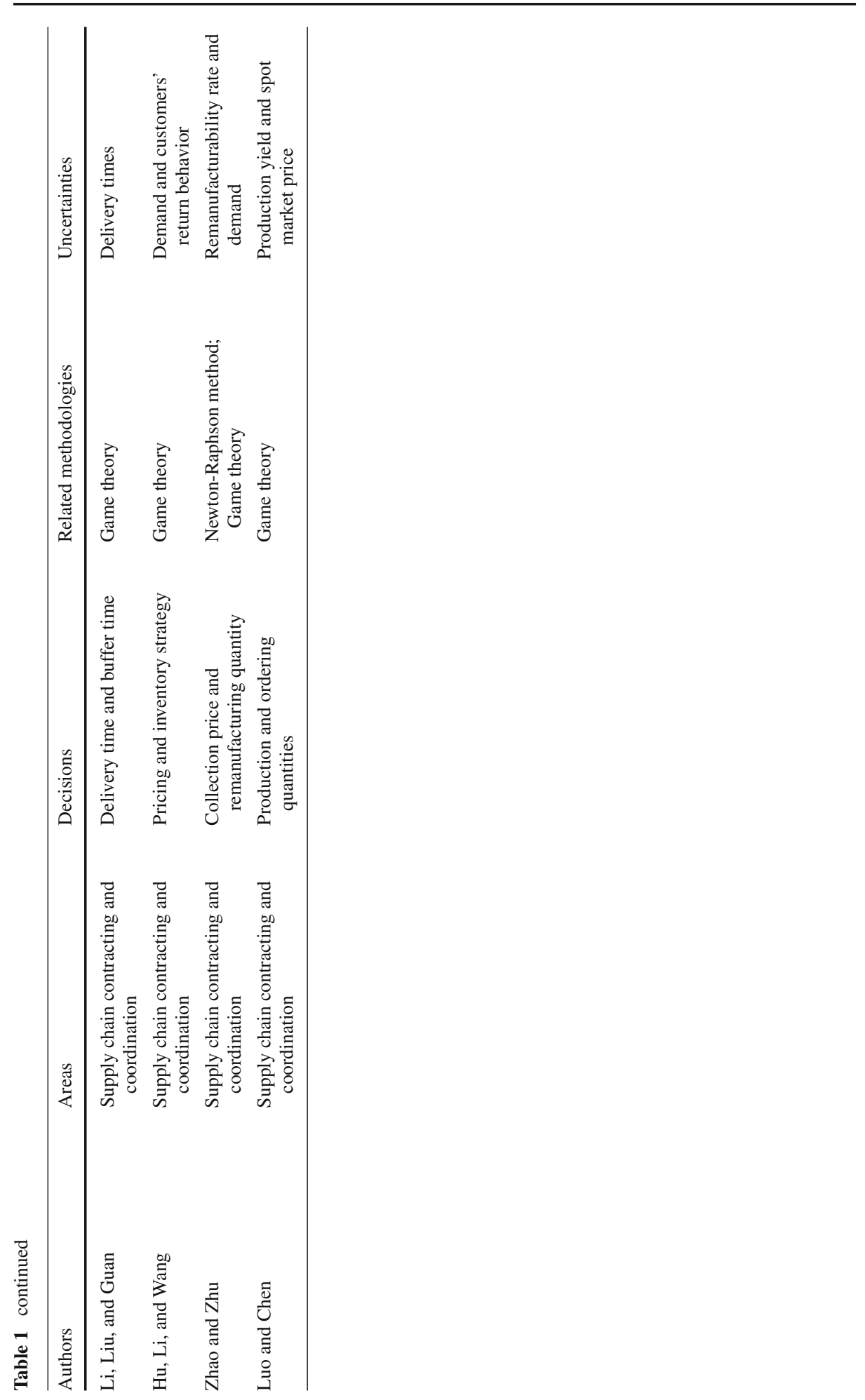


contract in different scenarios. Some numerical examples are provided to explore the impacts of government price regulations on the coordination mechanism. One key finding is that it is necessary for supply chain partners to adjust the original contracts after demand disruptions when there are no price regulations. However, the supply chain partners would rather utilize the original contracts if the demand increases substantially and the government regulates the price.

$\mathrm{Li}$, Liu, and Guan (2017) discuss the diversity of payment contracts in the assembly system, their subsequent effects on each member's optimal strategy, and the system's overall cost. They study a decentralized assembly system consisting of a downstream manufacturer and two suppliers with different channel powers. The authors consider three payment schemes engaged with the two suppliers: on-delivery payment, on-agreed-time payment, and readyto-assemble payment. They derive the equilibrium delivery time decisions of suppliers and the optimal setting of the manufacturer's buffer time. They show that the delivery times of suppliers are cost-driven and time-related, and the buffer time of the manufacturer can balance the production lead times of the supplier. In addition, the supply chain achieves optimality when the core supplier chooses an on-agreed-time payment contract, and the general supplier adopts a ready-to-assemble payment contract.

$\mathrm{Hu}, \mathrm{Li}$, and Wang (2017) study the vendor-managed consignment inventory contract and the consignment contract with revenue sharing under uncertain demand and customers' uncertain return behaviors. The authors compare the two consignment contracts with both benefit and risk considerations. They find that both the retailer and whole supply chain will gain higher profit from the consignment contract with revenue sharing, but they will share a high level of risk under this contract. The supplier can benefit more from the vendor-managed consignment inventory contract and his share of risk depends greatly on his share of the total cost. Both profit and risk decrease with regard to the level of uncertainty associated with the customer return.

Zhao and Zhu (2017) explore the revenue-sharing mechanism between a remanufacturer and a retailer in a truck engine remanufacturing supply chain. Considering two types of uncertainties, the stochastic remanufacturability rate and the random demand, the authors develop a revenue-sharing contract model. A Newton-Raphson method is adopted to solve the implicit function under the non-uniform demand distribution case. Next, they prove that the proposed revenue-sharing contract can bring win-win opportunities for both the remanufacturer and the retailer because the retailer can share expected revenues and subsidies, an incentive to encourage collection activities. Based on the data collected for remanufactured truck engines, a numerical example is provided to illustrate the application of the proposed model that benefits both players.

Luo and Chen (2017) explore the value of option contracts in a supply chain composed of a components supplier with random yield and a manufacturer who assembles components into finished products. Meeting the deterministic market demand in the presence of a spot market, both the supplier and the manufacturer can replenish components from the spot market with a random price. They derive solutions for the optimal production policy in the integrated system, and they pursue the manufacturer's optimal ordering policy and the supplier's optimal production policy in the decentralized system with and without option contracts. They propose that in the absence of option contracts, the whole supply chain will achieve poor performance because the manufacturer tends to over-order while the supplier under-produces. With option contracts, on the other hand, both the manufacturer's order and the supplier's production can be coordinated, and the optimal supply chain performance can be achieved. 


\section{Concluding remarks}

In the above sections, we have concisely examined each important research area on innovative supply chain optimization models with multiple uncertainty factors. In summary, Table 1 provides the essential characteristics of the papers featured in this special issue. In particular, we highlight the specific areas, decisions, related methodologies, and the sources of uncertainties associated with the papers. We believe that the papers featured in this special issue not only have many important insights, but also they have laid a solid foundation for future research to develop more innovative optimization models for supply chains facing multiple uncertainty factors.

Acknowledgements The guest editors would like to express their sincere thanks to Editor-in-Chief Professor Endre Boros and Publication Manager Katie D'Agosta for their kindest support in the development of this special issue.

\section{References}

Ai, X., Chen, J., \& Ma, J. (2012). Contracting with demand uncertainty under supply chain competition. Annals of Operations Research, 201(1), 17-38.

Arena, M., Arnaboldi, M., \& Azzone, G. (2010). The organizational dynamics of enterprise risk management. Accounting Organizations and Society, 35(7), 659-675.

Arena, M., Arnaboldi, M., \& Azzone, G. (2011). Is enterprise risk management real? Journal of Risk Research, 14(7), 779-797.

Babich, V., Burnetas, A. N., \& Ritchken, P. H. (2007). Competition and diversification effects in supply chains with supplier default risk. Manufacturing and Service Operations Management, 9(2), 123-146.

Chiu, C. H., \& Choi, T. M. (2016). Supply chain risk analysis with mean-variance models: A technical review. Annals of Operations Research, 240(2), 489-507.

Choi, T. M., Chiu, C. H., \& Chan, H. K. (2016). Risk management of logistics systems. Transportation Research (Part E), 90, 1-6.

Colicchia, F. S. (2012). Supply chain risk management: A new methodology for a systematic literature review. Supply Chain Management: An International Journal, 17(4), 403-418.

Fahimnia, B., Tang, C. S., Davarzani, H., \& Sarkis, J. (2015). Quantitative models for managing supply chain risks: A review. European Journal of Operational Research, 247(1), 1-15.

Govindan, K., \& Chaudhuri, A. (2016). Interrelationships of risks faced by third party logistics service providers: A DEMATEL based approach. Transportation Research Part E: Logistics and Transportation Review, 90, 177-195.

Govindan, K., \& Fattahi, M. (2017). Investigating risk and robustness measures for supply chain network design under demand uncertainty: A case study of glass supply chain. International Journal of Production Economics 183, 680-699.

Govindan, K., \& Jepsen, M. B. (2016). Supplier risk assessment based on trapezoidal intuitionistic fuzzy numbers and ELECTRE TRI-C: A case illustration involving service suppliers. Journal of the Operational Research Society, 67(2), 339-376.

Guler, M., \& Bilgic, T. (2009). On coordinating an assembly system under random yield and random demand. European Journal of Operational Research, 196(1), 342-350.

Heckmann, I., Comes, T., \& Nickel, S. (2015). A critical review on supply chain risk: Definition, measure and modeling. Omega, 52, 119-132.

Lalmazloumian, M., Wong, K. Y., Govindan, K., \& Kannan, D. (2016). A robust optimization model for agile and build-to-order supply chain planning under uncertainties. Annals of Operations Research, 240(2), 435-470.

Lawrence, V. S., Atan, Z., Peng, P., Rong, Y., Schmitt, A. J., \& Sinsoysal, B. (2016). OR/MS models for supply chain disruptions: A review. IIE Transactions, 48(2), 89-109.

Li, X., Li, Y., \& Cai, X. (2013). Double marginalization and coordination in the supply chain with uncertain supply. European Journal of Operational Research, 226(2), 228-236.

Nagurney, A., Daniele, P., \& Shukla, S. (2016). A supply chain network game theory model of cybersecurity investments with nonlinear budget constraints. Annals of Operations Research, doi:10.1007/s10479016-2209-1. 
Supply \& Demand Chain Executive and IHS. (2012). Benchmarking supplier risk: A survey of the supply chain. http://www.ihs.com/info/sc/a/supplier-risk.aspx.

Snyder, L. V., Atan, Z., Peng, P., Rong, Y., Schmitt, A. J., \& Sinsoysal, B. (2016). OR/MS models for supply chain disruptions: A review. IIE Transactions, 48(2), 89-109.

Tang, S. Y., Gurnani, H., \& Gupta, D. (2014). Managing disruptions in decentralized supply chains with endogenous supply process reliability. Production and Operations Management, 23(7), 1198-1211.

Tang, S. Y., \& Kouvelis, P. (2011). Supplier diversification strategies in the presence of yield uncertainty and buyer competition. Manufacturing and Service Operations Management, 13(4), 439-451.

Wu, D. D., Zheng, L., \& Olson, D. L. (2014). A decision support approach for online stock forum sentiment analysis. IEEE Transactions on Systems Man and Cybernetics, 44(8), 1077-1087. 